NBER WORKING PAPER SERIES

\author{
INTELLECTUAL CAPITAL AND THE \\ FIRM: THE TECHNOLOGY OF \\ GEOGRAPHICALLY LOCALIZED \\ KNOWLEDGE SPILLOVERS
}

\author{
Lynne G. Zucker \\ Michael R. Darby \\ Jeff Armstrong
}

Working Paper No. 4946

\author{
NATIONAL BUREAU OF ECONOMIC RESEARCH \\ 1050 Massachusetts Avenue \\ Cambridge, MA 02138 \\ December 1994
}

This research has been supported by grants from the National Science Foundation (SES 9012925), the University of California Systemwide Biotechnology Research and Education Program, the University of California Systemwide Pacific Rim Research Program, the UCLA Center for American Politics and Public Policy, and the UCLA Institute of Industrial Relations. We acknowledge very useful comments on earlier drafts from Woon Gyu Choi, Harold Demsetz, Mark Grady, Marvin B. Lieberman, Maximo Torero, J. Fred Weston and seminar participants at UCLA. The authors thank Woon Gyu Choi who provided program code used to estimate a modified two-stage Heckman procedure and Keunkswan Ryu who provided helpful advice on its implementation. We are indebted to a remarkably talented team of post-doctoral fellows Zhong Deng, Julia Liebeskind, and Yusheng Peng and research assistants Paul J. Alapat, Lynda J. Kim, Kerry Knight, and Edmundo Murrugara, Amalya Oliver, Alan Paul, Erika Rick, and Maximo Torero. This paper is part of NBER's research program in Productivity. Any opinions expressed are those of the authors and not those of the National Bureau of Economic Research.

() 1994 by Lynne G. Zucker, Michael R. Darby and Jeff Armstrong. All rights reserved. Short sections of text, not to exceed two paragraphs, may be quoted without explicit permission provided that full credit, including $\odot$ notice, is given to the source. 


\title{
INTELLECTUAL CAPITAL AND THE \\ FIRM: THE TECHNOLOGY OF \\ GEOGRAPHICALLY LOCALIZED \\ KNOWLEDGE SPILLOVERS
}

\begin{abstract}
We examine the effects of university-based star scientists on three measures of performance for California biotechnology enterprises: the number of products in development, the number of products on the market, and changes in employment. The "star" concept which Zucker, Darby, and Brewer (1994) demonstrated was important for birth of U.S. biotechnology enterprises also predicts geographically localized knowledge spillovers at least for products in development. However, when we break down university stars into those who have collaborated on publications with scientists affiliated with the firm and all other university stars, there is a strong positive effect of the linked stars on all three firm-performance measures and little or no evidence of an effect from the other university stars.

We develop a new hypothesis of geographically localized effects of university research which is consistent with market exchange: Geographically localized effects occur for scientific discoveries characterized by natural excludability, those which can be learned only by working with discoverers or others who have received the knowledge through working together in the laboratory. Natural excludability results in intellectual capital, a transitory form of human capital, embodied in particular scientists whose services must be employed in order to practice the discovery. Contractual and/or ownership relationships occur between firms and the university scientists with intellectual capital and importantly determine firm productivity and growth.
\end{abstract}

Lynne G. Zucker

Department of Sociology

University of California

Los Angeles, CA 90024-1551

and NBER

Jeff Armstrong

Department of Economics

University of California

Los Angeles, CA 90024
Michael R. Darby

Anderson Graduate School of

Management

University of California

Los Angeles, CA 90024-1551

and NBER 


\title{
INTELLECTUAL CAPITAL AND THE FIRM: THE TECHNOLOGY OF GEOGRAPHICALLY LOCALIZED KNOWLEDGE SPILLOVERS
}

\author{
by Lynne G. Zucker, Michael R. Darby, and Jeff Armstrong
}

Zvi Griliches (1992) has surveyed the importance of R\&D spillovers as a major source of endogenous growth in recent "New Growth Theory" models and the difficult empirical search for their existence. Lynne G. Zucker, Michael R. Darby, and Marilynn B. Brewer (1994) have recently demonstrated that "intellectual capital," particularly where and when "star" scientists at the leading edge of basic bioscience are active, is a principal determinant of both the location and timing of the founding of new biotechnology enterprises (NBEs) in the United States. ${ }^{1}$ These results provide strong further evidence of the empirical relevance of geographic localization of knowledge spillovers as was indicated in Zoltan J. Acs and David B. Audretsch (1988 and 1993), Adam B. Jaffe (1989), Jaffe, Manuel Trajtenberg, and Rebecca Henderson (1993), Audretsch and Maryann P. Feldman (1993), Acs, Audretsch and Feldman (1994), and Edwin Mansfield (1994). ${ }^{2}$ This paper uncovers important evidence on the technology by which geographically localized knowledge spillovers operate: What might appear using standard methodology and data sets as geographically localized external economies for enterprises located near university stars turn out to exist only for those enterprises which are linked to particular star professors by contract or ownership -- that is, by market exchange.

We are re-examining the current diffuse notion of university spillovers, attempting to correctly specify models of spillovers within a small range of biotechnology-using industries by identifying the key university-industry linkages along which flow of knowledge 
is most likely to occur. In this paper, we do not address cross-industry spillovers -- where borrowing takes place between research teams (Griliches 1992, p. S36) -- although we expect that close attention to links across industries, perhaps along professional lines, might also yield a market exchange interpretation.

We are developing a methodology that permits correct specification of market exchange where it has heretofore been invisible. ${ }^{3}$ We do so by linking existing publicly available data sets together in ways that have not been done before, allowing us to construct the links between the basic science (using data bases created by and for scientists) and industry (using data bases created by and for firms). In so doing, we are able to construct high validity, high specificity measures without becoming focussed on a single innovation case study. ${ }^{4}$ By concentrating on genetic sequences and firm-specific products and employment, we are able to combine basic-science data with data from multiple industries from pharmaceuticals to instrumentation, agriculture, and brewing. This variety of industries is illustrated by such NBE products currently on the market or in development as a hepatitis $B$ vaccine, drugs to combat anemia in kidney dialysis patients, a diagnostic test for testicular cancer, nematodes for control of navel orange worm, modified vegetable oils for improved nutrition and industrial lubrication, improved fermentation processes, and reversible color-change ultraviolet-sensitive ink. ${ }^{5}$

The results reported here, if they are confirmed for additional industries and locations, have great significance for the interpretation of geographically localized knowledge spillovers: (a) First, the welfare losses normally associated with uncompensated externalities are not present. ${ }^{6}$ (b) Second, the question of why some apparent knowledge spillovers -- as in biotechnology -- are geographically localized while others -- as in high- 
temperature superconductivity -- are not appears to be intimately related to what Zucker, Darby, and Brewer (1994) termed intellectual capital, in particular whether the discovery in question is characterized by "natural excludability." (c) University policies which limit professors' ability to contract freely with and to establish ownership positions in firms may protect norms of disinterested science at the cost of limiting technology transfer and local development in scientific areas characterized by natural excludability.

We shall return to these points below, but first we must turn to the substantive case which suggested the basic hypothesis. The empirical work in this paper is based on an extension for California only of the existing large scientist-article-citation-university-instituteenterprise-economy data base presented in Zucker, Darby, and Brewer (1994). ${ }^{7}$ The data set was extended in five principal ways: (a) a telephone census verified existing 1989 and added 1994 employment data for California NBEs, (b) data on the numbers of products in development and on the market in 1989 was collected for these NBEs from Bioscan, (c) a second telephone survey of California star scientists was used to illuminate patterns of linkage between NBEs and stars not affiliated with NBEs, (d) patterns of coauthorship by stars not affiliated with NBEs were derived from the existing data base to uncover implicit linkages to NBEs, and (e) patenting activity by California stars reported in Entrez was examined to uncover differences according to the nature of the stars ties, if any, to local NBEs. ${ }^{8}$ The extended data base was used to examine the determinants of success for California NBEs with special emphasis on understanding the nature of geographically localized knowledge spillovers. California makes an ideal site for the study because of the early entry into both the science and industry of biotechnology, as well as the number of distinct locales where bioscience or both the science and industry have developed. 
Section I discusses and presents summary data on California biotechnology enterprises and their underlying scientific base and relates our methodology and measurements to the literature. Estimation methods are outlined in Section II. Section III presents empirical results on the determinants for California biotech enterprises of employment growth and the numbers of products in development and on the market. Section IV analyzes the implications of these results for the concept of geographically localized knowledge spillovers. A data appendix concludes the paper.

\section{Biotechnology Science and Industry in California}

Modern applications of biotechnology in the pharmaceutical, medical supply, chemical, agricultural, food-processing, brewing, and other industries emerged in the years following the 1973 discovery by Stanford professor Stanley Cohen and University of California-San Francisco professor Herbert Boyer of the basic technique for recombinant DNA (rDNA). ${ }^{9}$ Today biotechnology refers principally to the application of genetic engineering based upon taking a gene from one organism and implanting it in another (rDNA) and production of the outcome of this process. ${ }^{10}$ While the production part of biotechnology can be done by many firms, the selection of promising lines and the gene transfer itself require very special skills and talents which were quite rare at least until very recently. Following Harold Demsetz (1988), we argue that mastery of this specialized body of knowledge played a central role in delineating the boundaries of biotechnology firms. Zucker, Darby, and Brewer (1994) showed the key role of leading-edge science in the birth of NBEs and we show here that role continued in determining the success and failure of 
these enterprises.

California has continued to play a leading role in both the basic science and its commercialization and, if it were a separate country, would rank third in both science and industry after the rest of the United States and Japan. California boasts one third of the U.S. universities with biotech-relevant departments receiving the highest ratings in the 1982 National Academy of Sciences reputational survey. ${ }^{11}$ California firms such as Amgen, Chiron, and Genentech are world leaders in biotechnology. These firms, along with other California NBEs, are among early entrants into commercial biotechnology, providing a sufficiently long track record for meaningful analysis of their patterns of performance and growth. Therefore, California is a suitable while still manageable subject for a study that develops techniques for identifying spillovers more precisely by identifying linkages with NBEs of star scientists affiliated with universities. ${ }^{12}$ Further, as we will discuss in more detail below, the pattern of our results for California at the aggregate level matches the pattern of results found for spillovers in Jaffe's nationwide study (1989).

\section{I.A. Describing California New Biotechnology Enterprises}

In the May 1994 telephone census described in the Data Appendix (Table A.1 is a variables list), we obtained usable data on 1989 and 1994 employment levels for 110 California New Biotechnology Enterprises (NBEs). As expected from Zucker, Darby, and Brewer (1994), 109 of these (99.1 percent) were located in those four of the state's eight functional economic areas as defined by the Bureau of Economic Analysis (BEA areas or simply BEAs) where star scientists also worked. Over forty percent of the NBEs are in the 
San Francisco Bay BEA and another third in the San Diego BEA. ${ }^{13}$

Table 1 shows a breakdown of the NBEs by their age in 1989. Over a third of the NBEs are 9-10 years old (entered in 1980 or 1981), implying that a large number of the enterprises got their start around the time of the Genentech initial public offering in October 1980, a date considered a financial watershed in biotechnology commercialization (John Elkington 1985, pp. 59-60). This is also close to the peak in U.S. foundings of NBEs. We distinguish between firms founded specifically to exploit the new bioscience technologies (new biotechnology firms or NBFs) and subunits (including subsidiaries) of preexisting firms established to exploit these technologies (new biotechnology subunits or NBSs). Age is measured from date of founding for NBFs and date of entry into biotech for other NBEs. NBEs in principle also include organizations for which insufficient data exist to establish whether NBF or NBS and, as in our sample, problematic organizations such as a joint venture between a NBF and a NBS. In our 110-NBE sample, there are $87 \mathrm{NBF}$ and 22 NBSs, which is only slightly higher a ratio of NBFs than the national average.

Since many NBEs are working on pharmaceuticals which typically require about ten years of development and testing prior to FDA approval, revenues and especially profits are generally nonexistent early in those firm's development and cannot provide a reliable indicator of success. Market value of the enterprise would do better, but less than half of the NBEs are publicly traded. As a result, for performance measures we focus on employment growth from 1989 to 1994 (DELEMP) and the numbers of products in development and on the market in 1989 (PRODDVLP and PRODMKT) as measures of enterprise success. Associated categorical variables are DGROW $(-1,0$, or 1 as the NBE's employment decreased, stayed the same, or increased 1989-1994) and DDEVMKT (1 if the 
NBE has any specific products with specific applications in development or on the market, 0 otherwise). Table 2 presents means and standard deviations of these measures and FIRMAGE for the full sample as well as broken down by BEA area and DGROW.

Note that the San Diego BEA, with the youngest average enterprise age, has the largest value of DGROW indicating the highest ratio of increasing to decreasing employment NBEs. The Other BEAs, with the oldest average age, actually have 4 more NBEs with shrinking than with increasing employment. However, this may represent a shake-out phenomenon as older NBEs either succeed and grow substantially or begin to shrink since the mean DELEMP of 246.8 employees for the Other BEAs is substantially larger than in either the San Diego or San Francisco Bay BEAs. As will be discussed below, the relatively high ratios of products on the market to products in development for the San Diego BEA and for both types of non-growing enterprises is a negative indicator suggesting emphasis on diagnostics, reagents and instruments rather than applying rDNA to create human therapeutics. Human therapeutics take much longer to market but also are the segment where blockbuster products arise with potential yields in the hundreds of millions and billions of dollars per year.

\section{I.B. California Star Scientists and Their Ties to Enterprises}

As indicated by the organizational location given on their publications, 55 star scientists worked in California NBEs and universities during 1976-1989..$^{14}$ Of these, 10 gave a NBE as their location during this period; we term these stars "amiliated" with the

NBE given. ${ }^{15}$ It might appear that the other stars are pure academic scientists, devoid of 
commercial concerns and ties, but that conclusion in a number of cases would be misleading. Two previous substantial case studies done by one of the authors and her project team colleagues (Julia Liebeskind, Amalya Oliver, Zucker, and Brewer 1993) and our telephone survey of California star scientists indicate that academic stars may simultaneously be linked to specific NBEs in a number of different ways. There appear to be a number of patterns beyond exclusive direct employment, often as CEO or other principal, and ownership in an enterprise. Given the distinguished achievement of these scientists a number of them also maintain university positions although sometimes as adjunct professors. Scientists who choose to remain principally academics have a variety of financial ties to enterprises, including full or part ownership, employment, exclusive and nonexclusive consulting contracts, and membership on scientific advisory boards. These ties generally establish ownership rights and the star's compensation for the fruits of the collaboration.

While most academics at major U.S. research universities are aware of colleagues who have become millionaires or billionaires as a result of starting a firm while retaining an university appointment, the picture of explicit contractual linkage to enterprises is at sharp variance with the picture familiar to economists of how geographically localized spillovers work. The standard economic notion is that by being near the universities where cutting-edge research is being done, employees of local enterprises will hear of important discoveries first and thus be able to utilize them before others are aware of their existence, much less their value. In this paradigm, the information in the discovery is a public good freely available to those who incur the costs of seeking it out in the groves of academe. It is further assumed that scientific discoveries have only fleeting value unless formal intellectual-property-rights mechanisms effectively prevent use of the information by 
unlicensed parties; i.e., absent patents, trade secrets, or actual secrecy, the value of a discovery erodes quickly as the information diffuses.

Zucker, Darby, and Brewer (1994) have a different view: Scientific discoveries vary in the degree to which others can be excluded from making use of them. Inherent in the discovery itself is the degree of natural excludability: if the techniques for replication are not widely known prior to the discovery, then any scientist wishing to build on the new knowledge must first acquire hands-on experience. ${ }^{16}$ If he or she cannot gain access to a research team or laboratory setting with that know-how, then working in that area may be very difficult if not impossible. Natural excludability then is a transitory source of "intellectual capital" yielding supranormal labor income for scientists who embody the breakthrough knowledge. Scientists earn such returns until the discovery has sufficiently diffused to eliminate the quasi-rents in excess of the normal returns on the cost of acquiring the knowledge as a routine part of a scientist's human capital.

As information diffuses after a discovery, the associated intellectual capital of a person who embodies the information declines both because the supranormal returns decline as there are more scientists using the information competitively and because there is less time remaining until the information is part of routine science and thus no longer capable of earning supranormal returns. The value of intellectual capital created by a new discovery increases as the discovery involves techniques that must be learned first-hand through collaboration or apprenticeship; that is, to the extent that they possess the "natural excludability" necessary for relatively long-lasting supranormal returns. ${ }^{17}$

The breakthrough discoveries involved in modern biotechnology have fundamentally changed how bioresearch is done. Once a new life form has been created and its use 
identified and sufficiently demonstrated, then those specific inventions are alienable from their creator through intellectual property mechanisms. However, the new techniques used in their creation have exhibited both high natural excludability and immense commercial value. Therefore, it is not surprising that Zucker, Darby, and Brewer (1994) found that where and when stars were actively publishing were important determinants of where and when enterprises built to use their special knowledge would be formed.

Since star scientists could simultaneously provide immense value to both great research universities and NBEs, many chose to do both. One way to identify those scientists wearing two hats is to examine the coauthorship pattern of stars unaffiliated with NBEs. A star is "linked" to a NBE if the star publishes an article with one or more scientists in the NBE while he or she is located at a university in the same BEA as the NBE. We hypothesize that such locally linked stars are the main channel by which university star scientists have influenced the success of NBEs.

They do so in two primary ways. First, linked star scientists provide access to and information about discoveries with potential commercial value made in their own and other university-based labs. Zucker, Darby, Brewer, and Yusheng Peng (1994) have shown that organizational boundaries serve as informational envelopes within which valuable information characterized by natural excludability is much more likely to be diffused than to those outside the organization. So, by being in both the university and the NBE, the linked star is able to convey knowledge of processes and techniques which would otherwise not be available to the NBE.

Second, the linked university stars are able to maintain both links because of the very high quality of their input. Central to understanding how these dual affiliations work is the 
case study finding that bioscientists act as individual actors, as opposed to acting as agents of their primary ties, whether to the university or the firm (Zucker, Brewer, Oliver, and Liebeskind 1993). These bioscientists can exercise their expertise independently primarily because they are recognized as having excellent "scientific taste" in the selection of research problems and using exceptional care and expertise in executing that research. ${ }^{18}$ By exercising their "scientific taste" these linked stars judge the likely payoff of different lines of bioscience research and advise the NBE concerning their relative merit. We expect that the scientific advisory boards play a similar role, and plan to investigate them in later research. Linked stars, while they generally have a significant financial interest in the NBE, also often have the advantage of being part of a broad external "network for evaluation," providing the basis for high quality input in product development decisions (Zucker 1991). ${ }^{19}$

As described in the Data Appendix, we examined every article through 1989 reporting a gene-sequence discovery written by a star located in a California university or NBE. We classified for each star whether he or she was affiliated with a NBE on that article or, if not, whether any scientists from a NBE in the local BEA were coauthors on the article. Accordingly, for each article the star was classified as amliated with or linked to a specific NBE or untied to any NBE. ${ }^{20}$ For the empirical work reported in Section III, we use counts of these classified articles, but a simpler count of individual stars is reported in the upper panel of Table 3.

Working with BEA-level data, we have a total of 64 stars who ever published in California. After eliminating double-counting of stars who moved across BEAs within California, this corresponds to the 55 individual stars who ever published with a California 
NBE or university through 1989 . Of these, 10 were ever affiliated with one or more NBEs, and another 8 were linked to one or more NBEs in the same BEA where they were publishing. A few of the remaining 37 stars have been affiliated with NBEs outside of California or published with NBEs outside of their California BEA, but those are not relevant for our current study of geographically localized knowledge spillovers.

The lower panel of Table 3 presents summary data on the patents granted for genetic sequence discoveries through 1993 that list one of the 55 star scientists who published in a California NBE and/or university during 1976-1989. As we discussed above, while natural excludability leads to the embodiment of certain knowledge and techniques in individuals, there is also a role for formal intellectual property rights. When the knowledge is implemented to create alienable, potentially commercially valuable discoveries, patents offer an important mechanism for appropriating returns. Thus, the patenting of discoveries by stars is an indication of expected commercial value of their discoveries.

The data presented in Table 3 show that those stars affiliated with NBEs are very different in their patenting activity compared to university stars: half have patented discoveries versus only 15.6 percent of the university stars. Among the university stars, a quarter of those linked to specific NBEs in the same BEA have patented discoveries compared to 13.5 percent of those not tied to such NBEs. Although the numbers are small, the standard $\chi^{2}(2)$ test rejects the hypothesis of independence.

Comments on earlier versions of this paper suggest that it is commonly thought -especially among academics -- that the very best scientists are unlikely to be involved with firms or to patent their discoveries. This presumption may rest on the idea that scientific norms of openness and disinteredness in fact contribute to the advance of science and are 
most likely to be observed by the best scientists. ${ }^{21}$ Commercialization of high science is presumed to be done by lesser scientists, perhaps in the role of bridge-builders between science and technology (Lieberman 1978). However, as seen in Table 4, patented scientists are generally more widely cited than unpatented scientists and affiliated scientists are more cited than linked scientists who in turn are more cited than untied scientists. To take the extreme cases, affiliated scientists with patents are cited 6.5 times as frequently as untied scientists without patents. Citation frequency is the standard indicator of scientific eminence in quantitative work. ${ }^{22}$ It appears that work done either in or in collaboration with firms is quite productive in terms of influence on future research. We cannot identify whether this reflects the increased value of aligned scientific and economic incentive systems, better facilities available for commercially relevant work, or simply that only the best of even the elite star scientists have the opportunity to work in or with new biotech enterprises.

In Table 5, the means for our three performance measures are tabulated according to whether the NBE has stars affiliated with it or not and according to whether the NBE has stars linked to it or not. There is a clear pattern of NBEs with affiliated or linked stars having more products in development and on the market and having more employment growth, although only the latter differences are robustly significant. ${ }^{23}$ With this motivation that the star concept may prove useful in analyzing performance of NBEs, we turn to relating the methods used here to other work in the literature.

\section{I.C. Relation to Other Empirical Work}

In describing the general features of our data base, we have implicitly raised 
questions concerning prior models and related empirical measures of innovative inputs, the knowledge generation process, and outputs of that process. Innovative inputs have generally been treated as measured by the resources invested in them, most often R\&D expenditures. The underlying assumption that equal investment in $R \& D$ produces equal innovative returns is easily falsifiable and recently patents have been seen as a better measure of inputs than output of the innovative process. ${ }^{24}$ We know that most scientists have very low productivity, with most of the scientific output typically produced by the top 1 or 2 percent of all scientists working in a specific area (Harriet Zuckerman 1967, Crane 1972, Paul D. Allison, J. Scott Long, and Tad K. Krauze 1982). Thus, we are concerned with identifying and locating the most productive, star scientists (all of whom were located in universities initially), their explicit linkages to firms, and actual measures of their productivity in the firm linkage. The latter is measured here by the number of articles reporting geneticsequence discoveries that are published either with the firm listed explicitly as the star's affiliation or which include firm scientists as coauthors.

Just as we are concerned with more precise specification of innovative inputs, we are also concerned with improving the precision of innovative outputs at the firm level and, particularly, of introducing specific economic outcomes as measures of innovative performance. The best recent papers in the literature have refined the measure of patents as an outcome with appropriate weighting or screening and introduced the number of product innovations.

Unfortunately, the latter measure is defined rather broadly on the basis of lists of product, process, service, and management innovations reported in trade journals related to manufacturing industries (K.L. Edwards and T.J. Gordon 1984). Moreover, Acs and 
Audretsch (1988, p. 681) report that these innovations are primarily (86.7 percent) modest improvements that update existing products -- conceptually far removed from our idea of significant outputs from the innovative process. Further, the innovations data set in use only includes products on the market (Acs and Audretsch 1988 and 1993), again removed from the innovation process and yet not measuring the impact of the process on the economic success of the firm.

In contrast, we separately measure three different aspects of the economic impact of inventive activity: the number of products in development (generally close to the inventive activity), the number of products on the market (indicating successful development), and net growth in employment (indicating successful development and marketing of products). Each can be seen as a successive step in moving from the initial invention to the impact on economic performance of the firm. Although we use only crosssectional data in the work reported here, we plan to exploit available information to develop time series on the first two measures for 1987-1994, as well as less complete data on employment changes at the firm level over the same period.

\section{Estimation Methods}

Because of the nature of the processes which we will be estimating, we use two approaches to estimation: (a) poisson regressions are used for products in development and on the market and (b) a modified Type II Tobit procedure following Takeshi Amemiya (1985) is used for change in employment. Each is outlined briefly below. 


\section{II.A. Products in Development and on the Market}

While a significant number of NBEs list no products in development or on the market as shown in Table 2, we count one or more such products for most NBEs. In the results reported in Section III, we estimate poisson regressions on each of these count variables using the LIMDEP package. ${ }^{25}$ As discussed in Jerry Hausman, Bronwyn H. Hall, and Griliches (1984), the poisson process is the most appropriate statistical model for count data such as we are dealing with here. The poisson regression fits the logarithm of the poisson parameter as the sum of the coefficients times the variable values for the firm. While the magnitude of the coefficients are not easily interpretable, positive coefficients indicate a higher expected value of the dependent variable.

\section{II.B. Employment Changes}

We saw in Table 2 that 52.7 percent of the NBEs increased employment during 19891994, 12.7 percent had unchanged employment, and 34.5 percent decreased employment. The employment gains were typically much larger than the employment losses; so total employment of the $110 \mathrm{NBEs}$ in the sample increased by over 11,000 people. Obviously, one eighth of the mass at zero is inconsistent with the data generating process assumed in OLS and other standard estimation methods. The Heckman (1976) two-step procedure is appropriate to deal with such an apparently non-linear data generating process. ${ }^{26}$

We hypothesize that the NBE's employment decision can be captured by a two-step process: In the first-stage the firm decides whether to expand, contract, or stay the same. 
This first-stage decision is latent, and a NBE's propensity to alter its size is observed only after some critical threshold level is exceeded where the need to change size exceeds fixed adjustment costs. In the second stage, the NBE also attempts to achieve a desired level of employees, a latent variable, which is observed for NBEs that do in fact alter their size.

The latent variable $S^{*}$ represents the propensity of NBEs to alter their size. For each observation, $S^{*}$ is specified as follows:

$$
\mathrm{S}^{*}=\mathrm{x}_{1}{ }^{\prime} \alpha+\mathrm{u}_{1}
$$

where $x_{1}$ is a vector of characteristics affecting the NBE's decision to alter its size. We do not observe $S^{*}$ but rather its sign:

$$
\begin{gathered}
S \quad-1 \text { if } S^{*}<\mu_{l} \\
0 \text { if } \mu_{l} \leq S^{*}<\mu_{u} \\
+1 \text { if } S^{*} \geq \mu_{u}
\end{gathered}
$$

where $\mu_{l}$ and $\mu_{u}$ are the lower and upper bound thresholds outside of which a NBE implements a decision to alter its size.

Let $\mathrm{D}^{*}$ represent the unobserved desired change in total employees as a function of a vector of characteristics:

$$
D^{*}=x_{2}^{\prime} \beta+u_{2}
$$

$D^{*}$ is observed only for NBEs where $S$ is plus or minus one, that is, $D=D^{*}$ if $S^{*} \geq \mu_{u}$ or $S^{*}<\mu_{l}$

Given this structure, it is appropriate to employ a two-stage estimation procedure which, first, predicts whether employment will increase, remain the same, or decrease and, second, estimates the size of the change for those NBEs that actually do change. The second-stage estimation can be interpreted in terms of correcting for selectivity biases which 
would otherwise occur in the coefficients and variance-covariance matrix estimated in OLS for those NBEs with nonzero DELEMP.

The selectivity-corrected specification is straightforward: The conditional expectation functions assuming that $u_{1}$ and $u_{2}$ are distributed bivariate normal, $\operatorname{BVN}\left(0,0,1, \sigma_{2}^{2} \rho\right)$ are:

$$
\begin{aligned}
\mathrm{E}(\mathrm{DELEMP} \mid \mathrm{S}=-1) & =\mathrm{E}\left(\mathrm{DELEMP} \mid \mathrm{S}^{*}<\mu_{l}\right) \\
& =\mathrm{x}_{2}^{\prime} \beta+\rho \sigma_{2} \mathrm{E}\left(\mathrm{u}_{1} \mid \mathrm{u}_{1}<-\mathrm{x}_{1}{ }^{\prime} \alpha+\mu_{l}\right) \\
& =\mathrm{x}_{2}{ }^{\prime} \beta+\rho \sigma_{2}\left\{-\phi\left(\mathrm{x}_{1}{ }^{\prime} \alpha-\mu_{l}\right) /\left(1-\Phi\left(\mathrm{x}_{1}{ }^{\prime} \alpha-\mu_{l}\right)\right\}\right.
\end{aligned}
$$

for the sample of NBEs that contract and where $E(\bullet)$ is the expectations operator, $\phi$ and $\Phi$ the standard-normal density and distribution functions. For NBEs that expand, the conditional expectation function is:

$$
\begin{aligned}
\operatorname{E}(D E L E M P \mid S=+1) & =\mathrm{E}\left(\mathrm{DELEMP} \mid \mathrm{S}^{*} \geq \mu_{\mathrm{u}}\right) \\
= & \mathrm{x}_{2}{ }^{\prime} \beta+\rho \sigma_{2} \mathrm{E}\left(\mathrm{u}_{1} \mid \mathrm{u}_{1} \geq-\mathrm{x}_{2}{ }^{\prime} \alpha+\mu_{\mathrm{u}}\right) \\
= & \mathrm{x}_{2}{ }^{\prime} \beta+\rho \sigma_{2}\left\{-\phi\left(\mathrm{x}_{1}{ }^{\prime} \alpha-\mu_{\mathrm{u}}\right) / \Phi\left(\mathrm{x}_{1}{ }^{\prime} \alpha-\mu_{\mathrm{u}}\right)\right\}
\end{aligned}
$$

Note that $x_{1}$ need not be constrained to equal $x_{2}$. This offers important flexibility since the star-scientist variables enter significantly into $x_{2}$ but not into $x_{1}$. Let $\lambda(\bullet)$ equal the term in curled brackets on the bottom line of each conditional expectation function (4a) and (4b) and let $\gamma=\rho \sigma_{2}$ its coefficient. This $\lambda(\bullet)$ is known as the Inverse-Mills Ratio (or IMR). For $\rho$ not equal to plus or minus one, this model is a modified version of the Type II Tobit procedure described by Amemiya (1985).

To implement the modified Heckman (1976) procedure, first-staged ordered probit estimates of $\alpha$ and $\mu_{u}$ (with $\mu_{l}$ normalized to 0 ) are used to construct estimated values of $\lambda(\bullet)$ for each NBE satisfying either $S=-1$ or $S=+1$. As Ryu (1993) has shown, the standard Type II Tobit two-stage estimation procedure produces a biased and inconsistent variance- 
covariance matrix due to a heteroscedastic and correlated error structure. Following Ryu (1993), Choi (1993) derives an unbiased and consistent variance-covariance matrix for the modified Type II Tobit used here which we use to obtain exact standard errors in the results below. ${ }^{27}$

\section{Empirical Results}

In this section we report results on three different measures of NBE performance: the number of products the NBE has in development as of 1990 , the number of products it has on the market at that time, and the net change in its employment over the five years following 1989. None of these measures are by any means perfect substitutes for changes in value of the enterprise as measures of success. However, many biotechnology firms are small start-up ventures which are not yet publicly traded and other NBEs are subunits of much larger enterprises not primarily involved in biotechnology. Thus, the sample size would be unacceptably reduced from the 76 NBEs for which we have data if we restricted ourselves to those for which enterprise value was also available. ${ }^{28}$ Nonetheless, these three indicators are interesting in and of themselves from organizational, economic, and policy perspectives and are likely to reflect spillover effects if they exist.

As indicated above, in these estimates we use a set of variables built by counting the number of articles reporting genetic sequence discoveries and written by each star located in California universities or NBEs, according to whether for each article the star was affiliated with, linked to, or not tied to each of the 110 NBEs in the data set. We constructed an analogous set of measures (also described in the Data Appendix) in which 
individual stars were counted as affiliated, linked, or untied without regard to article weighting. Since the results for the latter construct were essentially the same as those reported, we do not include them here. ${ }^{29}$

\section{III.A. Products in Development}

The number of products the NBE has in development as of 1990 (PRODDVLP) is taken from the NBE's listing in Bioscan (see the Data Appendix for details). Generally, these products are in various stages of clinical trials or field testing, although in some cases the listed products may be at earlier stages of development or have received F.D.A. market approval but not yet be marketed. Among the three indicators examined, this measure appears to be most closely related to success in application of the new biotechnologies and least affected either by use of other technologies or by differences in business strategy (e.g., in-house production and/or marketing vs. joint agreements with established pharmaceutical firms).

We first examine the results of a poisson regression in the spirit of Jaffe (1989). Model $\mathbf{a}$ in Table 6 explains products in development by the number of gene-sequencediscovery articles written by stars in local universities not affiliated with any NBE (WSUNABEA), by whether or not the NBE is a NBF (as opposed to a biotech subunit of a pre-existing firm), by the NBE's age, and by whether or not the NBE utilizes the rDNA technology. Model b broadens model a by also including the number of gene-sequencediscovery articles written by stars affiliated with the NBE (WSAFFIL). Consider first model a: As expected, the NBE's age and its use of the rDNA technology both contribute 
significantly and positively to the number of products in development. Interestingly, the new dedicated biotech firms are significantly more likely to be developing new products than incumbent firms. Finally, we see that the stars concept which was used by Zucker, Darby, and Brewer (1994) to identify the scientists around which NBFs and NBSs would be built also appears to work here to uncover important, positive, significant geographically localized spillover effects of local universities on the success of enterprise R\&D efforts in the manner of Jaffe (1989) and Acs, Audretsch, and Feldman (1994). These results all persist in model b, although the addition to the poisson regression of the significantly positive number of stars affiliated with the NBE generally reduces both the magnitude and t-statistics for the other explanatory variables.

Models $\mathrm{c}$ and $\mathrm{d}$ are identical to models $\mathrm{a}$ and $\mathrm{b}$, respectively, except that the number of articles written by university stars is broken down into those written in collaboration with scientists from the NBE (WSLINKLO) and the remaining (WSUNTILO). The explanatory power of the regressions are substantially and significantly improved by relaxing the implicit constraint that research done in the university has the same effect on enterprise R\&D productivity whether or not it is done in collaboration with the enterprise's scientists. In fact, the coefficient on articles written by local university stars not in collaboration with the NBE loses its significance and nearly vanishes in magnitude. What had appeared to be an undifferentiated geographically localized knowledge spillover seems to have resulted from a specification error: If we did not have the data set required to identify which university stars were linked to which enterprises, then this study would have confirmed the previous findings. Instead we find that no such indiscriminate spillovers are apparent in biotechnology. 
It is interesting that when WSLINKLO is admitted to the regression separately, neither WSAFFIL nor RTECH retain their significance. We believe that this should not be taken to mean that having affiliated stars or using the rDNA technology are irrelevant. For example, enterprises with affiliated stars are most likely to attract university stars to collaborate with them. ${ }^{30}$ The enterprises with links to university stars are able to most effectively acquire and use the results of ongoing university research; linked stars become the conduits for the information and for evaluation of different lines of research related to potential product development.

\section{III.B. Products on the Market}

The number of products the NBE has on the market as of 1990 (PRODMKT) also is taken from the NBE's listing in Bioscan (see the Data Appendix for details). Although some of these products result from the application of the new biotechnologies, by and large, given the typical decade-long FDA approval process for human therapeutics, the products on the market are largely reagents and instruments used in applying the technology rather than the result of the new biotechnologies themselves.

These differences between products on the market and products in development rationalize the differences between the results reported in Tables 7 and 6 . In Table 7, the coefficients on DNBF and RTECH are both negative and significant which we believe reflects the fact that NBEs which are engaged primarily in applying the new technologies are likely to have fewer products than their suppliers. Nonetheless, FIRMAGE (measured from the date of entry into biotech) and WSAFFIL or, when it is entered, WSLINKLO have 
a positive effect on the number of products on the market. As to the latter effects, the positive coefficients reflect the fact that the most successful NBEs using the new biotechnologies are the ones most likely to have products which reached the market.

\section{III.C. Changes in Employment}

Table 8 reports the results from the first-stage ordered probit estimation. These estimates are useful primarily as a basis for correction for selectivity bias in the equations reported in Table 9 but do uncover an interesting pattern of industry dynamics. The coefficient estimates indicate that an enterprise is more likely to increase employment and less likely to decrease employment if it uses rDNA technology to produce human therapeutics and if it is younger. We will see below, however, that FIRMAGE is positive in determining the size of the NBE's employment increase. What we have identified in the first-stage estimates appears to be a sorting phenomenon in which as the enterprise matures, it either begins to grow more rapidly or else to shrink according to whether or not its strategy is proving successful. This increasing probability of decline or failure is in contrast to the findings for U.S. manufacturing plants generally reported by Timothy Dunne, Mark J. Roberts, and Larry Samuelson (1989), perhaps because it is so difficult to tell whether or not a young biotech enterprise is or is not achieving success.

Table 9 reports selectivity-corrected second-stage OLS estimates for change in the number of employees analogous to those reported for products in Tables 6 and 7 . The variance-covariance matrix has been corrected for the non-spherical error structure inherent in the Type II Tobit procedure as explained in Section II.B above. ${ }^{31}$ For models a and b 
in which linked stars do not enter separately neither university stars nor affiliated stars enter the regression significantly. In models $\mathrm{c}$ and $\mathrm{d}$, with university stars broken down into linked and other university stars, the linked stars are seen to have a significant positive effect as with the other performance variables. Once again, neither the other university stars nor the affiliated stars enter significantly.

Of the other variables, the only robustly significant effects are a positive coefficient on the use of the rDNA technology and another on the Inverse-Mills Ratio which signifies the importance of the selectivity bias correction.

\section{III.D. Summary of Empirical Results}

For all measures of firm performance, linked university stars have a significant positive effect while other local university stars and stars affiliated with the firm do not when all three variables enter the equation. For the variable most directly related to innovative activity, the number of products in development, there appears to be a significant classic geographically localized spillover effect from the number of local university stars. However, this disappears when university stars are broken down into those which have direct links to the specific firm and all others. While affiliated stars then do not have a measurable direct effect on firm performance, it should be noted that firms with affiliated stars are more likely to have linked stars. Further, the significant correlation between the linked- and affiliated-stars variables makes it difficult to separately identify their effects.

To provide a more intuitive feel for the data, Figure 1 plots by zip code some of the data underlying the results for the crucial variable of products in development. Large dots 
indicate locations where one or more stars are located and large dots in circles indicate which of those locations include linked stars. Scaled triangles indicate the number of products in development by firms with no linked or affiliated stars while scaled diamonds indicate the number of products in development by firms with linked and/or affiliated stars. Small dots represent firms with no products in development. While there is a small diamond and there are a few large triangles, it is clear that generally large firms with linked or affiliated stars are much more likely to have many products in development.

Thus for the biotechnology industry, we have provided strong evidence that apparent geographically localized knowledge spillovers in fact represent specific market exchange. Informal discussions with many of the linked scientists indicates that this exchange often takes place through equity sharing. With even a small degree of non-salvageability among the transacting parties--as when a firm's product development becomes uniquely dependent on a particular star scientist--coupled with a high degree of uncertainty, it is not surprising to observe such "vertical integration" as described by Klein, Crawford and Alchian (1978). While we await other researchers' results for additional industries and technologies, we hypothesize that apparent local spillovers generally may confound strong effects from university scientists directly involved with local firms and weak or nonexistent effects from all other university scientists.

\section{Conclusions}

Paul M. Romer (1990) shows that knowledge spillovers have substantial macroeconomic implication for growth and international trade. These implications result 
because investments in R\&D produce an output (characterized by Romer as a set of instructions) which is both nonrivalrous and at least partially excludable. ${ }^{32}$ Our empirical results suggest that what have been termed geographically localized knowledge spillovers do not seem to fit this definition of spillovers, at least in the case of biotechnology. In particular, because discoveries in this area are characterized by natural excludability and embodied in human capital and because transmitting the discovery to others requires the active participation of those with the knowledge, the technology cannot be characterized as a nonrivalrous set of instructions. ${ }^{33}$ Thus to the extent that our results generalize to other cases of apparent geographically localized knowledge spillovers, the inefficiencies derived in Romer's analysis are not present.

The standard notion of geographically localized knowledge spillovers is based on the idea that university scientists are pursuing disinterested basic research, the results of which can be most quickly put to commercial use by those enterprises located nearby who can most readily learn novel results from social ties between employees and university scientists or by attending informal seminars at the university.

Our picture of how the process in fact has worked in biotechnology is quite different. We find that all the parties involved (government and other funding agencies, universities, professors, and enterprises) are or can be connected by contractual and/or ownership ties in competitive markets. The most productive scientists generally are either employees of or collaborators with the enterprises. The government grants patent rights to universities (with a proviso for minimum royalty rates for discovering scientists) and rights of exploitation to scientists who embody any intellectual capital resulting from their work. As a result, the prices paid by government funding agencies are reduced both directly due to 
any expected patent royalties to universities and indirectly because competitive university salaries are lower, other things equal, in areas where faculty expect the possibility of receiving substantial outside income or wealth as a result of skills developed doing research at the university. Since these discoveries are characterized by natural excludability, the discovering scientists do not give away to enterprises the fruits of their intellectual capital but instead enter into contractual arrangements with existing firms or start their own firm in order to extract the supranormal returns available to those fortunate and talented enough to acquire that capital. In this way, we see that what appeared to others as a case of knowledge spillovers with resulting inefficiencies is in fact a standard case of market exchange of rivalrous and excludable goods. We believe that this geographically localized impact, like intellectual capital itself, is a transitory phenomenon during the important initial period of industry development resulting from a major, commercially valuable scientific breakthrough characterized by natural excludability.

The empirical results in this paper are restricted to evidence on geographically localized knowledge spillovers in the California biotechnology industry. The reorientation in interpretation, we believe, is more generally applicable to any cases where natural excludability is important. Further, we hypothesize that it is precisely these cases where geographically localized effects of university research on industry are to be found. Without natural excludability, the output of research more closely corresponds to Romer's set of instructions which can be utilized anywhere (and everywhere in the absence of intellectual property rights). As with the example of high-temperature superconductors, location of discoveries and of production are disjoint since the labor of the discoverers is not required in production. 
Intellectual capital, when linked to the firm through market exchange mechanisms including ownership, significantly accelerates firm productivity and growth. A simple story, but one with profound implications for understanding the channels through which commercializable scientific discoveries alter the economy. 


\section{Data Appendix}

A detailed description of the basic data sets developed for the Project on "Intellectual Capital, Technology Transfer, and the Organization of Leading-Edge Industries: The Case of Biotechnology" (Lynne G. Zucker, Marilynn B. Brewer, and Michael R. Darby, Principal Investigators) is presented in Zucker, Darby, and Brewer (1994). These data will be archived upon completion of the project in the Data Archives at the UCLA Institute for Social Science Research. The project has been housed at and supported in part by ISSR.

The summary definitions of the variables used in this paper are provided in Table A.1. A description of the construction of variables new in this paper follows. Table A.2 provides summary statistics for the variables.

\section{A.1. Measures of NBE Performance}

Our basic source for employment growth from 1989 to the winter or spring of 1994 is a telephone census conducted in May 1994. We attempted to conduct telephone interviews for all 182 California NBEs in the Zucker, Darby, and Brewer (1994) data base.

We initially sought information on employment levels in 1984, 1989, and 1994. Attempting to obtain 1984 information generally resulted in refusals to participate. However, we obtained almost complete coverage of NBEs which we could locate by limiting our questions to confirmation of the employment levels for 1989 (EMP89) already in the data base (which indicated to respondents that we were independently knowledgeable about their business) and obtaining either end of 1993/beginning of 1994 or current (May 1994) employment 
levels. From the 182 initial cases, we obtained 110 useable observations for EMP94 as detailed in Table A.3 (upper part).

We next attempted to add information on how many products each of these $\mathbf{1 1 0}$ NBEs had in development (PRODDVLP) or on the market (PRODMKT) in 1990 by referring to issues of Bioscan for that year. In a few cases missing NBEs were listed in 1989 or 1991 issues in which case those numbers were accepted. However, as detailed in the remainder of Table A.3, for 32 smaller NBEs no listing was found which reduces the sample size to 78 NBEs where either of these two variables or their categorical transform DDEVMKT is used. In the analyses we include as a control variable whether the NBE reported using the recombinant DNA technology (indicated by RTECH $=1$ ) which is most closely related to the star measure. Missing values on that variable (i.e., no report on technologies used) further reduces the sample size from 78 to 76 NBEs with complete data.

In order to present a more current picture of the firms' products, Tables A.4 and A.5 give a 1994 (not 1990) 1-in-10 sample of products in development and 1-in-20 sample of products on the market which may be useful for those readers not familiar with the range of products and industries to which biotechnology has been applied and informative to the rest.

\section{A.2. Defining Stars and Their NBE Afriliation or Linkage}

Zucker, Darby, and Brewer (1994) demonstrate the key role played in determining where and when NBEs are founded by intellectual capital, in particular by where and when leading frontier scientists ("stars") are actively publishing. We first shall review how they 
defined stars and then develop the special measures used in this paper.

Given the fundamental role of rDNA in modern biotechnology, a very important measure of research success in the basic science is the discovery of nucleotide sequences that determine the characteristics of proteins and other molecules. In the earlier stages of the project, GenBank was used to identify all articles reporting genetic sequence discoveries up to $1990 .{ }^{34}$ Worldwide 337 leading researchers (the "stars") were identified on the basis of the number of genetic sequence discoveries and articles reporting them up to 1990 for which they were an author. These 337 stars were listed as authors on 4,315 distinct articles in major journals. These articles were hand collected and used to identify and locate institutional affiliations at the time of publication for each of our stars and their coauthors who were either other stars or "collaborators" (7,718 scientists worldwide). This hand coding was necessary because available machine-readable data bases give only the location of the first author who, given the authorship conventions of the field, is rarely a star scientist.

In our extension of the Zucker, Darby, Brewer (1994) data set, we developed two ways of measuring the local stars from the point of view of our 110 sample NBEs: by counting individual local stars and by counting the number of articles written by local stars. For the individual measures, a star is said to be "afmliated" with a NBE if that NBE is ever listed by the star as an affiliation during 1976-1989. A star is said to be "linked" to a NBE if, while listing a university in the same BEA as the NBE, he or she has ever coauthored with a scientist (star or collaborator) who listed the NBE as his or her affiliation on that article. $^{35}$ Thus, linked stars are those at universities who have specific ties to particular nearby NBEs as identified by their publishing activities with the NBE. 
The star scientist variables calculated for this paper are those with the initial letters ST listed in Table A.1. Each variable is observed for the cross section of 110 California NBEs for which EMP94 was obtained (see above). Each NBE is geocoded as being located in one of the eight California functional economic areas (BEA areas) as defined by the U.S. Bureau of Economic Analysis.

For each of the BEAs, we produce counts of the total number of stars who have published while working in a local university or NBE broken down into those who were at any time affiliated with any NBE in the BEA (STAFFBEA) and the remaining stars (STUNABEA) who worked in the BEA only in universities. ${ }^{36}$ Either of these variables will have the same value for all NBEs located in a given BEA.

Three NBE-specific star variables were then created: a count of the number of stars who have worked with the specific NBE (STAFFIL), the number of stars in the BEA not counted in STAFFIL who are linked to the NBE (STLINKLO), and finally the number of BEA stars who are neither affiliated with any NBE nor linked to this NBE (STUNTILO). Thus, total university-based stars (STUNABEA) is the sum of STLINKLO and STUNTILO while STAFFIL is the count of the subset of the STAFFBEA stars who are affiliated with the specific NBE.

Counting individual stars in this way as all in one category or another may give a misleading picture of the degree of involvement with a NBE; so alternative article-weightedstar variables (beginning with WS in Table A.1) were calculated with each star allocated to affiliated, linked, or untied categories on an article-by-article basis.

The two article-weighted star variables that are the same for each NBE in a given BEA are: the summed number of articles written by stars listing universities located in the 
BEA (WSUNABEA) and the summed number of articles written by stars listing any NBE in the BEA at the time of writing (WSAFFBEA).

Finally, three NBE-specific article-weighted star variables were then created: WSAFFIL, WSLINKLO, and WSUNTILO, corresponding to the individual star variables discussed above. 


\section{REFERENCES}

Acs, Zoltan J., and David B. Audretsch, "Innovation in Large and Small Firms: An Empirical Analysis," American Economic Review, September 1988, 78: 678-690.

Acs, Zoltan J., and David B. Audretsch, "Innovation and Technological Change: The New Learning," Advances in the Study of Entrepreneurship, Innovation, and Economic Growth, 1993, ․: 109-142.

Acs, Zoltan, David B. Audretsch, and Maryann P Feldman, "R\&D Spillovers and Innovative Activity," Managerial and Decision Economics, 1994, 15: 131-138.

Adams, James D., and Adam B. Jaffe, "The Span of the Effect of R\&D in the Firm and Industry," paper presented at the NBER Summer Institute on Productivity, Cambridge, MA, July 28, 1994.

Allison, Paul D., J. Scott Long, and Tad K. Krauze, "Cumulative Advantage and Inequality in Science," 1982, American Sociological Review, 47: 615-625.

Amemiya, Takeshi, Advanced Econometrics, Cambridge, MA: Harvard University Press, 1985.

Audretsch, David B., and Maryann P Feldman, "The Geography of Innovation and Production," in Centre for Economic Policy Research, The Location of Economic Activity: New Theories and Evidence, conference proceedings volume, Vigo, Spain: Consorcio de la Zona Franca di Vigo, 1993.

Bania, Neil, Randall Eberts, and Michael Fogarty, "Universities and the Startup of New Companies: Can We Generalize from Route 128 and Silicon Valley," Review of Economics and Statistics, November 1993, in press.

Blaug, Mark, Who's Who in Economics: A Biographical Dictionary of Major Economists, 1700-1986, 2nd ed., Cambridge, MA: The MIT Press, 1985. ["Preface" at pp. vii-ix, argues for using of frequency of citations with scholarly eminence.]

Cheung, Steven N.S., "Ronald Harry Coase," in John Eatwell, Murray Milgate, and Peter Newman, eds., The New Palgrave: A Dictionary of Economics, vol. 1, London: The Macmillan Press Ltd., 1987.

Choi, Woon Gyu, "The Discount Rate Policy Reaction Function of the Monetary Authority: An Application of a Sample Selectivity Model," paper presented in the Econometrics Workshop, UCLA Economics Department, November 2, 1993.

Coase, Ronald H., "The Problem of Social Cost," Journal of Law and Economics, October 1960, 3: 1-44. 
Coase, Ronald H., "The Lighthouse in Economics," Journal of Law and Economics, October 1974, 17: 357-76.

Cohen, Stanley, A. Chang, Herbert Boyer, and R. Helling, "Construction of Biologically Functional Bacterial Plasmids in vitro," Proceedings of the National Academy of Sciences, 1973, 70: 3240-3244.

Colander, David, "Research on the Economics Profession," Journal of Economic Perspectives, Fall 1989, 3: 143 .

Crane, Diana, Invisible Colleges: Diffusion of Knowledge in Scientific Communities, Chicago, Ill.: University of Chicago Press, 1972.

Demsetz, Harold, "The Theory of the Firm Revisited," Journal of Law, Economics, and Organization, Spring 1988, 4: 141-161.

Dorfman, Nancy S., "Route 128: The Development of a Regional High Technology Economy," in David Lampe, ed., The Massachusetts Miracle: High Technology and Economic Revitalization, Cambridge, MA: MIT Press, 1988.

Dunne, Timothy, Mark J. Roberts, and Larry Samuelson, "The Growth and Failure of U.S. Manufacturing Plants," Quarterly Journal of Economics, November 1989, 104: 671-698.

Eccles, Robert G., and Dwight B. Crane, Doing Deals: Investment Banks at Work, Boston, MA: Harvard Business School Press, 1988.

Edwards, K.L., and T.J. Gordon, "Characterization of Innovations Introduced on the U.S. Market in 1982," report to the U.S. Small Business Administration by The Futures Group under Contract No. SBA-6050-0A-82, 1984.

Eisenberg, Rebecca S., "Proprietary rights and the norms of science in biotechnology research," Yale Law Journal, December 1987, 97: 177-231.

Elkington, John, The Gene Factory, New York: Carroll \& Graf Publishers, Inc., 1985.

Faulkner, R. R., and A. B. Anderson, "Short-term Projects and Emergent Careers: Evidence from Hollywood," American Journal of Sociology, 1987, 92: 879-909.

Greene, William H., LIMDEP: User's Manual and Reference Guide, Version 6.0, Bellport, NY: Econometric Software, Inc., 1992.

Griliches, Zvi, "Patent Statistics as Economic Indicators: A Survey," Journal of Economic Literature, December 1990, 28:1661-1707. 
Griliches, Zvi, "The Search for R\&D Spillovers," Scandinavian Journal of Economics, 1992 Supplement, 94: 29-47.

Hausman, Jerry, Bronwyn H. Hall, and Zvi Griliches, "Econometric Models for Count Data with an Application to the Patents-R\&D Relationship," Econometrica, July 1984, 52: 909-938.

Heckman, James, "The Common Structure of Statistical Models of Truncation, Sample Selection, and Limited Dependent Variables and a Simple Estimator for Such Models," Annals of Economic and Social Measurement, 1976, 5: 475-492.

Institute for Scientific Information, Science Citation Index, ISI Compact Disc Editions, machine readable data base, Philadelphia: Institute for Scientific Information, various years through 1993.

Jaffe, Adam B., "Real Effects of Academic Research," American Economic Review, December 1989, 79: 957-970.

Jaffe, Adam B., Manuel Trajtenberg, and Rebecca Henderson, "Geographic Localization of Knowledge Spillovers as Evidenced by Patent Citations," Quarterly Journal of Economics, August 1993, 63: 577-598.

Jones, Bryan D., and Arnold Vedlitz, "Higher Education Policies and Economic Growth in the American States," Economic Development Quarterly, February 1988, 2 (1): 78-87.

Jones, Lyle V., Gardner Lindzey, and Porter E. Coggeshall, eds., An Assessment of ResearchDoctorate Programs in the United States: Biological Sciences, Washington: National Academy Press, 1982.

Klein, Benjamin, R. Crawford, and Armen Alchian, "Vertical Integration, Appropriable Rents, and the Competitive Contracting Process, Journal of Law and Economics, October 1978, 21: 297-326.

Lieberman, Marvin B., "A Literature Citation Study of Science-Technology Coupling in Electronics," Proceedings of teh IEEE, January 1978, 66: 5-13.

Liebeskind, Julia, Amalya Oliver, Lynne G. Zucker, and Marilynn B. Brewer, "Using Social Networks to Gain Competitive Advantage: Sourcing Scientific Knowledge in New Biotechnology Firms," paper presented at the Strategic Management Conference, September 1993.

Mansfield, Edwin, "Academic Research Underlying Industrial Innovations: Sources, Characteristics, and Financing," Review of Economics and Statistics, in press 1994. 
Merton, Robert K., "Motive Forces of the New Science," in Robert K. Merton, Science, Technology and Society in Seventeenth-Century England, 1970. [pp. 80-111]

Peters, H. P. F.. and A. F. J. van Raan, "A Bibliometric Profile of Top-Scientists: A Case Study in Chemical Engineering," Scientometrics, 1994, 29(1): 115-136.

Plomp, R., "The Highly Cited Papers of Professors as an Indicator of a Research Group's Scientific Performance," Scientometrics, 1994, 29(3): 377-393.

Romer, Paul M., "Endogenous Technological Change," Journal of Political Economy, 1990, 98 (Supplement): S71-S102.

Ryu, Keunkwan, "Modified Heckman's Two-Step Estimation and Specification Test in Sample Selectivity Models," working paper, UCLA Economics Department, 1993.

Smilor, Raymond W., George Kozmetsky, and David V. Gibson, Creating the Technopolis: Linking Technology, Commercialization, and Economic Development, Cambridge, MA: Ballinger Publishing Co., 1988.

Taubes, G., Nobel Dreams. Power, Deceit and the Ultimate Experiment, New York: Random House, 1986.

Thompson, James D., Organizations in Action, New York, NY: McGraw-Hill, 1967.

U.S. Department of Health and Human Services, National Center for Biotechnology Information, Entrez: Sequences and Entrez: References, Release 9.0, machine readable data base, Bethesda, MD: National Library of Medicine, National Institutes of Health, February 15, 1994.

Watson, James D., The Double Helix: A Personal Account of the Discoery of the Structure of DNA. New York: Norton, 1968. [1981]

Zucker, Lynne G., "Markets for Bureaucratic Authority and Control: Information Quality in Professions and Services," Research in the Sociology of Organizations, 1991, 8: 157189.

Zucker, Lynne G., Michael R. Darby, and Marilynn B. Brewer, "Intellectual Capital and the Birth of U.S. Biotechnology Enterprises," National Bureau of Economic Research Working Paper No. 4653, February 1994. 
Zucker, Lynne G., Michael R. Darby, Marilynn B. Brewer, and Yusheng Peng, "Collaboration Structure and Information Dilemmas in Biotechnology: Organizational Boundaries as Trust Production," in Roderick M. Kramer and Thomas Tyler, eds., Trust in Organizations, Newbury Park, CA: Sage, 1994 in press. [UCLA Institute for Social Science Research Working Papers in the Social Sciences, Volume 6, Number 2]

Zucker, Lynne G., Marilynn B. Brewer, Amalya Oliver, and Julia Liebeskind, "Basic Science as Intellectual Capital in Firms: Information Dilemmas in rDNA Biotechnology Research," working paper, UCLA Institute for Social Science Research, 1993.

Zuckerman, Harriet, "Nobel Laureates in Science: Patterns of Productivity, Collaboration, and Authorship," American Sociological Review, 1967, 32: 391-403. 


\section{FOOTNOTES}

1. NBEs include both new biotechnology firms formed to exploit the new technologies and divisions, subsidiaries, or other units of incumbent firms which enter the biotechnology field.

2. Nancy S. Dorfman (1988), Bryan D. Jones and Arnold Vedlitz (1988), Raymond W. Smilor, George Kozmetsky, and David V. Gibson (1988), Neil Bania, Randall Eberts, and Michael Fogarty (1993), and James D. Adams and Jaffe (1994) also indicate geographic localization of knowledge spillovers.

3. We are, of course, tempted to call this a cloud chamber for Adam Smith's "invisible hand," but could not stoop so low.

4. See Griliches (1992, pp. S31-S33) on the pitfalls along the path of narrowly focussed research.

5. See Tables A.4 and A.5 in the Data Appendix for more examples.

6. It should not be entirely surprising that where the holders of the valuable knowledge are few in number, contracts can be negotiated which eliminate the effects of potential externalities; see Ronald H. Coase (1960). Coase (1974) also observed that economists are overly prone to assume externalities, as in lighthouses, where market contracts can in fact exist. Steven N.S. Cheung $(1987$, p. 456$)$ notes that Coase objected to the term The Coase Theorem since "what he did was to specify the conditions under which the traditional theorem of exchange becomes operative." This paper aims to show that those conditions may also apply in the case of what has been considered to be geographically localized spillovers.

7. This work was funded by a grant to Zucker and Darby for "Linking California Universities and Scientists to the Biotechnology Industry" from the University of California Systemwide Biotechnology Research and Education Program.

8. For Entrez, see U.S. Department of Health and Human Services (1994).

9. Cohen, Chang, Boyer, and Helling (1973).

10. The other basic technology is cell fusion (also termed monoclonal antibodies, MABs, or hybridomas) in which lymphocytes are fused with myeloma cells to create rapidly proliferating antibody-producing cells.

11. The survey is reported in Lyle V. Jones, Gardner Lindzey, and Porter E. Coggeshall (1982). The eighteen U.S. universities with top-rated biotech relevant departments included California Institute of Technology, Stanford, and the University of California campuses at Berkeley, Los Angeles, San Diego, and San Francisco. 
12. In California, a relatively small number of star scientists list affiliations with a third category of organizations: research institutes and hospitals. Since these organizations are not generally considered in studies of geographically localized knowledge spillovers and there are no significant linkages between their stars and NBEs, we focus in this paper exclusively on stars who are located at some time in at least one California university or NBE.

13. Most, but not all, of the remainder are located in the Los Angeles BEA. The Sacramento (Davis) BEA is the fourth area with star scientists.

14. This method of locating scientists in organizations was developed and validated at an earlier stage of this project (Zucker, Brewer, Oliver, and Liebeskind 1993).

15. One of these 10 stars was affiliated sequentially with two NBEs over the period; the other nine stars were each affiliated with only one NBE.

16. Indeed natural excludability has created some problems for making the "enabling disclosure" that is required for a valid U.S. patent application. In order to obtain the seventeen-year monopoly granted by a patent the applicant must make a disclosure that will enable the public to practice the innovation once the patent expires. After some litigation and legislation, patents are now obtainable by biotech inventors who disclose their invention by placing a culture in a recognized public depositary. (See Rebecca S. Eisenberg 1987 for a discussion of this history.) Disclosure by deposit eliminates the inherent difficulty in disclosing the art used to obtain the invention so that it can be readily replicated.

17. In the limit, where the discovery can be easily incorporated into the human capital of any competent scientist, the discoverer(s) cannot earn any personal returns -- as opposed to returns to intellectual property such as patents or trade secrets. In the case of biotechnology, it may be empirically difficult to separate intellectual capital from the conceptually distinct value of cell cultures created and controlled by a scientist who used his or her nonpublic information to create the cell culture.

Besides natural excludability, the value of intellectual capital depends on the novelty and value of the discovery. For example, many discoveries have little or no value--whether monetary or nonmonetary. They are viewed as a dead-ends, of interest only within a few collaborations. The techniques and research program crawl along, diffusing slowly if at all.

18. Dual affiliations of bioscientists are a specific instance of a very general phenomenon in which individuals with exceptional quality of performance and productivity compared to others with similar kinds of skills come to have more than one simultaneous organizational affiliation (Zucker 1991). For example, top ranked physicians tend to have multiple affiliations with hospitals and top producers and directors are much more likely to have multiple contracts with independent film companies while others have none (R. R. Faulkner and A. B. Anderson 1987, Tables 2-4).

19. For similar internal firm use of external evaluative information, see Robert Eccles and Dwight Crane (1988, pp. 152-154) on the use of customer surveys to determine salary 
increases, bonuses, and promotion in investment banking.

20. The linked and untied distinction for our university stars may suggest James D. Thompson's (1967) distinction between boundary-spanning and core personnel. However, this analogy could prove misleading since nearly all the university stars have extensive contacts with organizations other than their own university and those stars who are actively involved in collaborations with firms typically do so for their own gain and not as part of their role in the university.

21. In the literature, the norms of science are said to dictate open disclosure to all other scientists, in an "invisible college" model of the flow of scientific information (Diana Crane 1972; Robert M. Merton 1970). However, as noted in Zucker, Darby, Brewer, and Peng (1994), whenever the discoveries have significant value, whether as pure science or as a commercial product, behavior has often systematically excluded potential competitors from access to that information (James D. Watson 1980; G. Taubes 1986). There is considerable evidence that this has occurred in bioscience, perhaps because of a divergence between the norms and the reward structure (Eisenberg 1987, especially pp. 197-205, 214-216, and 229231).

22. See, for example, Mark Blaug (1985, pp. vii-ix), David Colander (1989), H. P. F. Peters and A. F. J. van Raan (1994), and R. Plomp (1994).

23. In Table 5, we tested for equality of variance between the two groups. Where the hypothesis of equality was rejected at the 5 percent level, we report the $t$-test on the means for unequal variances. Otherwise, the t-test for equal variances is reported.

24. See Griliches (1990) for a review of the use of patent statistics as economic indicators.

25. See Greene (1992, pp. 539-549) for a discussion of this procedure.

26. Modeling this process as a one-step decision by using OLS or FGLS does not alter the qualitative findings nor significance of key variables though it does substantially reduce the model's overall goodness-of-fit. We implemented a specification test proposed by Ryu (1993) and found that our two-step procedure was a suitable specification.

27. Choi's substantive problem was the choice by the central bank to change the discount rate and, if so, by how much. We are indebted to Choi for providing his LIMDEP code to implement his procedure.

28. From an organizational sociology perspective, products in development is the preferred measure because it is conceptually most closely related to the R\&D function of intellectual capital. The extent to which scientific entrepreneurs are able to transfer intellectual capital value to the firm and the accuracy with which that capital is priced in the financial markets is the subject of future research.

29. These results will be made available upon request to any of the authors at least through 1999. 
30. WSLINKLO is positively and significantly correlated with WSAFFIL, and neither of these variables are significantly correlated with WSUNTILO.

31. Recall that these regressions are run only for the subset of NBEs for which employment changes were reported. We also tried percentage changes in employment with no significant differences in the qualitative results. We believe the level changes are easier to interpret and conform more closely to a Type II Tobit model and so report them here.

32. Nonrivalry implies that use by one person or enterprise does not reduce the amount available for use by others. Excludability, which refers to the ability of the owner of a good to prevent others from using it, can derive from technology, law, or both.

33. See Romer's (1990, pp. S74-S75) careful discussion of the key distinction between his technology and human capital.

34. See Zucker, Brewer, Oliver, and Liebeskind (1993). The rDNA technology devolved from high to routine science in the late 1980 s; so 1990 was a good year to end the literature base for identifying scientists possessing intellectual capital.

35. The distinction between affiliated and linked may be more form than substance: In some cases stars always list their university affiliation even though they are known to us to be simultaneously employed by or a principal in an enterprise.

36. They may also have worked in the BEA in the organizational category not considered for this paper: research institutes and hospitals. In addition, some stars moved across BEA boundaries and thus were counted multiple times in the extended data set (see Table 3 and the related discussion in Section I.B above). 
Table 1

Distribution of New Biotechnology Enterprises by Age in 1989

$\begin{array}{ccr}\text { NBE Age } & \begin{array}{c}\text { Number of } \\ \text { NBEs }\end{array} & \begin{array}{c}\text { Percent of } \\ \text { Total }\end{array} \\ 1 & 2 & 1.8 \\ 2 & 4 & 3.6 \\ 3 & 13 & 11.8 \\ 4 & 10 & 9.1 \\ 5 & 3 & 2.7 \\ 6 & 11 & 10.0 \\ 7 & 11 & 10.0 \\ 8 & 4 & 3.6 \\ 9 & 27 & 24.5 \\ 10 & 11 & 10.0 \\ 11 & 4 & 3.6 \\ 12 & 5 & 4.5 \\ 13 & 2 & 1.8 \\ 14 & 3 & 2.7 \\ \text { Total (all ages) } & 110 & 100.0\end{array}$


Table 2

Means and Standard Deviations of New Biotechnology Enterprise Characteristics by BEA Area and Enterprise Employment Growth

Variable

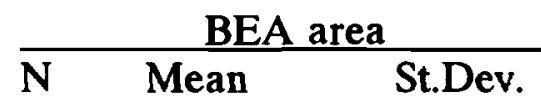

DGROW

48

DELEMP 48

DDEVMKT 33

PRODDVLP 33

PRODMKT 33

FIRMAGE 48

San Francisco BEA

$\begin{array}{rr}0.12 & 0.91 \\ 46.21 & 269.70 \\ 0.76 & 0.44 \\ 2.73 & 5.62 \\ 3.76 & 4.34 \\ 7.44 & 3.21\end{array}$

San Diego BEA

DGROW

DDEVMKT 29

PRODDVLP 29

PRODMKT 29

FIRMAGE 37
0.49

71.22

0.79

1.03

5.10

6.24
0.83

128.26

0.41

1.61

7.12

3.22

Other California BEAs

DGROW 25

DELEMP 25

DDEVMKT 16

PRODDVLP 16

PRODMKT 16

FIRMAGE 25

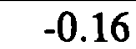

246.80

0.69

2.06

1.94

8.64

0.94

866.68

0.48

4.02

2.26

2.56

Full Sample

DGROW $110 \quad 0.18 \quad 0.92$

DELEMP $\quad 110 \quad 100.21$

DDEVMKT 78

0.76

PRODDVLP 78

1.96

3.88

$\begin{array}{lr}\text { FIRMAGE } & 110\end{array}$

7.31

456.82

0.43

4.22

5.35

3.18 \begin{tabular}{ccc}
\multicolumn{2}{c}{ Employment Growth } \\
\hline $\mathrm{N}$ & Mean & St.Dev.
\end{tabular}

\begin{tabular}{|c|c|c|}
\hline \multicolumn{3}{|c|}{ Employment Decreased } \\
\hline 38 & -1.00 & 0.00 \\
\hline 38 & -47.13 & 69.61 \\
\hline 27 & 0.77 & 0.42 \\
\hline 27 & 1.30 & 2.32 \\
\hline 27 & 3.15 & 5.03 \\
\hline 38 & 8.18 & 2.5 \\
\hline
\end{tabular}

\begin{tabular}{|c|c|c|}
\hline \multicolumn{3}{|c|}{ Employment Unchanged } \\
\hline 14 & 0.00 & 0.00 \\
\hline 14 & 0.00 & 0.00 \\
\hline 9 & 0.89 & 0.33 \\
\hline 9 & 0.78 & 1.30 \\
\hline 9 & 5.22 & 5.67 \\
\hline 14 & 9.29 & 3. \\
\hline
\end{tabular}

\begin{tabular}{lrr}
\multicolumn{3}{c}{ Employment Increased } \\
\hline 58 & 1.00 & 0.00 \\
58 & 220.93 & 603.93 \\
42 & 0.71 & 0.46 \\
42 & 2.64 & 5.35 \\
42 & 4.07 & 5.54 \\
58 & 6.26 & 3.21
\end{tabular}


Table 3

California Star Scientists

64 BEA-level Count of Stars Ever-Publishing Listing California Universities or NBEs

9 Multiple-counting of Stars Due to Moving across BEA Boundaries

55 Distinct Star Scientists Who Have Ever Published Listing California Universities or NBEs

10 Distinct Stars Ever Affiliated with California NBEs

8 Distinct Stars Ever Linked to One of More Local California NBEs

37 Distinct University-based Stars Never Affiliated with or Linked to a Local California NBE

Type of Star Number of Stars

Ever NBE Affiliated 10

Local NBE Linked

Untied (Never Linked $\quad 37$ or Affiliated)

Total Distinct Stars
Stars with No Gene-Sequence Patents

No. Percent
$5 \quad 50.0 \%$

$6 \quad 75.0 \%$

$32 \quad 86.4 \%$

$43 \quad 78.2 \%$

$12 \quad 21.8 \%$

$5 \quad 50.0 \%$

$2 \quad 25.0 \%$

$5 \quad 13.5 \%$
Stars with

Gene-Sequence Patents

No. Percent

55

Test for independence in a $3 \times 2$ contingency table: $\chi^{2}(2)=6.20^{* *}$

Significance levels: ${ }^{*} \leq 0.10,{ }^{* *} \leq 0.05,{ }^{* * *} \leq 0.01$ 
Table 4

Average Annual Citations to Genetic Sequence Articles by California Star Scientists

Type of Star

\begin{tabular}{ccc}
\multicolumn{3}{c}{ Stars' Gene-Sequence Patenting Activity } \\
\hline No Patents & Some Patents & All Stars
\end{tabular}

Ever NBE Affiliated

138.0

615.3

376.6

Local NBE Linked

147.6

303.2

186.5

Untied (Never Linked

95.1

188.7

107.8 or Affiliated)

Total Distinct Stars

107.4

385.5

168.1

Note: This table gives for each class the total number of citations in the Science Citation Index per scientist per year for the years 1982, 1987, and 1992 for all geneticsequence discovery articles authored or co-authored by each of the 55 California star scientists. 
Table 5

Distribution of New Biotechnology Enterprises by Star Affiliation or Star Linkage

Means, F-Statistics, and t-statistics

\section{PRODDVLP PRODMKT DELEMP}

$\begin{array}{lllc}\text { NBEs with Affiliated Stars } & 13.25 & 11.25 & 502.80 \\ \text { NBEs without Affiliated Stars } & 1.35 & 3.49 & 81.04 \\ \text { F-statistic (d.f.) for variances } & \begin{array}{l}13.03^{* * *} \\ (3,73)\end{array} & \begin{array}{l}7.44^{* * *} \\ (3,73)\end{array} & \begin{array}{c}2.58^{*} \\ (4,104)\end{array} \\ \text { t-statistic (d.f.) for means } & 2.41^{*} & 1.25 & 2.05^{* *} \\ & (3) & (3) & (108) \\ \text { NBEs with Linked Stars } & 10.80 & 4.80 & 506.80 \\ \text { NBEs without Linked Stars } & 1.36 & 3.82 & 80.85 \\ \text { F-statistic (d.f.) for variances } & 13.86^{* * *} & 1.54 & 2.50^{*} \\ & (4,72) & (4,72) & (4,104) \\ & & & \\ \text { t-statistic (d.f.) for means } & 2.07 & 0.39 & 2.07^{* *} \\ & (4) & (76) & (108)\end{array}$

Significance levels: ${ }^{*} \leq 0.10,{ }^{* *} \leq 0.05,{ }^{* * *} \leq 0.01$ 
Table 6

Estimates for Products in Development

Poisson Regressions, Dependent Variable: PRODDVLP

Variables

Coefficients (standard errors)

mod. a mod. b mod. $c \quad$ mod. $d$

Constant

$\begin{array}{llll}-3.3850^{* * *} & -2.4341^{* * *} & -1.9838^{* * *} & -1.9324^{* * *} \\ (0.4740) & (0.5251) & (0.4728) & (0.5275)\end{array}$

WSUNABEA

$\begin{array}{cc}0.0017^{* * *} & 0.0013^{* *} \\ (0.0006) & (0.0006)\end{array}$

WSUNTILO

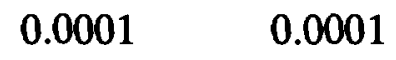

$(0.0007) \quad(0.0007)$

WSLINKLO

$\begin{array}{ll}0.3222^{* * *} & 0.3197^{* * *} \\ (0.0411) & (0.0428)\end{array}$

WSAFFIL

$0.0083^{* * *}$
$(0.0024)$

0.0006

(0.0026)

DNBF

$1.6232^{* * *}$

$1.4363^{* * *}$

$1.3504^{* * *}$

$1.3417^{* * *}$

$(0.3642)$

(0.3682)

(0.3664)

$(0.3686)$

FIRMAGE

$0.2088^{* * *}$
$(0.0278)$

$0.1395^{* * *}$

$0.1256^{* * *}$

$0.1209 * * *$

(0.0338)

(0.0294)

$(0.0365)$

RTECH

$0.9038^{* *}$

$0.6082^{* * *}$

0.2974

0.2845

(0.1769)

(0.1977)

(0.2000)

(0.2088)

Log-likelihood

$-196.06$

$-190.48$

$-169.48$

$-169.46$

Significance levels: ${ }^{*} \leq 0.10,{ }^{* *} \leq 0.05,{ }^{* * *} \leq 0.01$

Note: WSUNABEA $=$ WSUNTILO + WSLINKLO 
Table 7

Estimates for Products on the Market

Poisson Regressions, Dependent Variable: PRODMKT

Variables

Coefficients (standard errors)

mod. a mod. b mod. c mod. d

Constant

$1.3210^{* * *}$

$1.4630^{* * *}$

$1.4615^{* * *}$

$1.4953^{* * *}$

(0.2135)

(0.2206)

$(0.2178)$

(0.2228)

WSUNABEA

$\begin{array}{ll}-0.0004 & -0.0005 \\ (0.0004) & (0.0004)\end{array}$

WSUNTILO

$-0.0006 \quad-0.0006$

$(0.0004) \quad(0.0004)$

WSLINKLO
$0.1378^{* * *}$
$0.1143^{*}$
(0.0504)
(0.0640)

WSAFFIL

$$
\begin{gathered}
0.0062^{* *} \\
(0.0028)
\end{gathered}
$$$$
0.0024
$$$$
\text { (0.0035) }
$$

DNBF

$$
-0.3456^{* * *}
$$

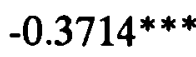

$-0.3398^{* *}$

$-0.3512^{* * *}$

$$
\text { (0.1330) }
$$

(0.1338)

(0.1330)

(0.1342)

FIRMAGE

$$
0.0803^{* * *}
$$

$0.0678^{* * *}$

$0.0673^{* * *}$

$0.0643^{* * *}$

(0.0206)

$(0.0215)$

(0.0213)

(0.0218)

RTECH

$-0.4990 * * *$

$-0.5595^{* * *}$

$-0.5778^{* * *}$

$-0.5880^{* * *}$

(0.1211)

(0.1256)

(0.1263)

(0.1275)

Log-likelihood

$-299.64$

$-297.57$

$-296.42$

$-296.20$

Significance levels: ${ }^{*} \leq 0.10,{ }^{* *} \leq 0.05,{ }^{* * *} \leq 0.01$

Note: WSUNABEA $=$ WSUNTILO + WSLINKLO 
Table 8

Estimates for Change in Employment

First-Stage Ordered Probit Maximum Likelihood Estimates

Dependent Variable: DGROW

\begin{tabular}{|c|c|c|}
\hline Variables & Coefficients & Std. Errors \\
\hline Constant & 0.7253 & 0.5547 \\
\hline DHUMDI & 0.4925 & 0.3207 \\
\hline \multicolumn{2}{|c|}{ DHUMTHXRTECH $0.7792^{* *}$} & 0.3100 \\
\hline DNBF & 0.1589 & 0.3796 \\
\hline FIRMAGE & $-0.1222^{* *}$ & 0.0554 \\
\hline Mu(upper $)^{\mathbf{a}}$ & $0.3613^{* * *}$ & 0.1144 \\
\hline \multicolumn{3}{|c|}{ Chi-squared $(4)=15.748^{* * *}$} \\
\hline
\end{tabular}


Table 9

Estimates for Change in Employment

Second-Stage Heckman Estimates

with Consistent Variance-Covariance Matrix

Dependent Variable: DELEMP for nonzero observations

\begin{tabular}{|c|c|c|c|c|}
\hline \multirow[t]{2}{*}{ Variables } & \multicolumn{4}{|c|}{ Coefficients (standard errors) } \\
\hline & mod. a & mod. $b$ & mod. $c$ & mod. d \\
\hline Constant & $\begin{array}{l}-65.175 \\
(248.06)\end{array}$ & $\begin{array}{l}-29.876 \\
(259.78)\end{array}$ & $\begin{array}{c}89.417 \\
(250.37)\end{array}$ & $\begin{array}{c}51.022 \\
(252.53)\end{array}$ \\
\hline WSUNABEA & $\begin{array}{l}-0.5295 \\
(0.4318)\end{array}$ & $\begin{array}{l}-0.5548 \\
(0.4349)\end{array}$ & - & - \\
\hline WSUNTILO & - & - & $\begin{array}{l}-0.7164 \\
(0.4282)\end{array}$ & $\begin{array}{l}-0.7130 \\
(0.4256)\end{array}$ \\
\hline WSLINKLO & - & - & $\begin{array}{l}130.74^{* *} \\
(63.875)\end{array}$ & $\begin{array}{l}172.17^{* *} \\
(78.157)\end{array}$ \\
\hline WSAFFIL & - & $\begin{array}{c}1.7767 \\
(4.0227)\end{array}$ & - & $\begin{array}{l}-4.3847 \\
(4.7782)\end{array}$ \\
\hline DNBF & $\begin{array}{l}-214.52 \\
(170.29)\end{array}$ & $\begin{array}{l}-221.10 \\
(170.41)\end{array}$ & $\begin{array}{l}-235.18 \\
(164.25)\end{array}$ & $\begin{array}{l}-225.45 \\
(163.82)\end{array}$ \\
\hline FIRMAGE & $\begin{array}{l}46.135^{* *} \\
(22.283)\end{array}$ & $\begin{array}{c}42.854^{*} \\
(23.426)\end{array}$ & $\begin{array}{c}32.604 \\
(22.448)\end{array}$ & $\begin{array}{c}36.439 \\
(22.719)\end{array}$ \\
\hline RTECH & $\begin{array}{l}324.63^{* *} \\
(132.83)\end{array}$ & $\begin{array}{l}313.05^{* *} \\
(134.97)\end{array}$ & $\begin{array}{c}259.67^{*} \\
(132.02)\end{array}$ & $\begin{array}{l}267.78^{* *} \\
(131.56)\end{array}$ \\
\hline IMR & $\begin{array}{l}190.64^{* *} \\
(75.484)\end{array}$ & $\begin{array}{l}185.32^{* *} \\
(76.332)\end{array}$ & $\begin{array}{l}162.17^{* *} \\
(74.530)\end{array}$ & $\begin{array}{c}166.33^{* *} \\
(74.189)\end{array}$ \\
\hline Adjusted $\mathbf{R}^{2}$ & 0.1275 & 0.1156 & 0.1659 & 0.1623 \\
\hline
\end{tabular}


Table A.1

Variables List

All observations are taken from the Zucker, Darby, and Brewer (1994) data base and defined for the 110 usable California-NBE observations in the 1994 telephone census except as noted.

DDEVMKT Categorical variable: 1 if $\max ($ PRODDVLP,PRODMKT) $>0 ; 0$ otherwise

DELEMP The change in the NBE's employment from 1989 to 1993: EMP94 -EMP89

DGROW Categorical variable: $-1,0$, or 1 as DELEMP $<,=,>0$

DHUMDI Categorical variable: 1 if the NBE is involved in human diagnostics; 0 otherwise $^{\mathrm{a}}$

DHUMTH Categorical variable: 1 if the NBE is involved in human therapeutics; 0 otherwise $^{\mathrm{a}}$

DNBF Categorical variable: 1 if the NBE is a NBF; 0 otherwise

EMP89 Employment levels in 1989 from the Zucker, Darby, and Brewer (1994) data base $^{\text {b }}$

EMP94 Employment levels in winter-spring 1994 from the telephone census

FIRMAGE Age of NBE in 1989; 1990 - date of founding

IMR Inverse-Mills Ratio as defined in Section II.B

$\mathrm{N} \quad$ Number of observations for a variable or regression after excluding missing observations

PRODDVLP Number of products in development by NBE

PRODMKT Number of products on the market by NBE

RTECH Categorical variable: 1 if the NBE uses the rDNA technology; 0 otherwise ${ }^{c}$

STAFFIL Affiliated stars: number of stars affiliated with the NBE at any time 1976$1989^{d}$

STAFFBEA Sum of affiliated stars: number of stars affiliated with any NBE in the NBE's BEA at any time $1976-1989^{\circ}$

STLINKLO Linked local stars: number of stars who (a) are linked to the NBE by coauthorship with a scientist affiliated with the NBE, (b) are located in a university in the NBE's BEA area when such a coauthored article was published, and (c) were not affiliated with the NBE at any time 1976-1989 
STUNABEA Unaffiliated local stars: number of stars who are located in a university in the NBE's BEA area but were not affiliated with any NBE in the BEA area at any time $1976-1989^{\circ}$

\section{STUNTILO Untied local stars: STUNABEA - STLINKLO}

WSAFFIL Article-weighted affiliated stars: sum over all stars of the number of articles written by each star while affiliated with the NBE at any time 1976-1989

WSAFFBEA Article-weighted sum of affiliated stars: sum over all stars of the number of articles written by each star while affiliated with any NBE in the NBE's BEA at any time $1976-1989^{\circ}$

WSLINKLO Article-weighted linked local stars: sum over all stars of the number of articles written by each star during 1976-1989 which (a) lists the star at a university located in the NBE's BEA, and (b) is coauthored with one or more other scientists who is (are) listed as affiliated with the NBE

WSUNABEA Article-weighted unaffiliated local stars: sum over all stars of the number of articles written by each star during 1976-1989 which (a) does not list the star as affiliated with any NBE and (b) does list the star as affiliated with a university located in the NBE's BEA

WSUNTILO Article-weighted untied local stars: WSUNABEA - WSLINKLO

Notes: a. Source: Bioscan, 1990 [1989 or 1991 in a few cases] ( $\mathrm{N}=78,32$ missing observations)

b. The telephone census described above confirmed these numbers closely in every case where they could be obtained; with two exceptions (see note a to Table A.3), the original data base numbers were retained to maintain time consistency.

c. Excludes those observations in the Zucker, Darby, and Brewer (1994) data base which have no technologies reported unless the NBE has licensed the Cohen-Boyer patent. ( $N=103,7$ missing observations)

d. In addition to any earlier articles, each of the stars affiliated with a NBE was so identified in at least one article published in 1988 or 1989.

rKULUVLF ivumoer oI prouucis in deveiopment oy ivDe

PRODMKT Number of products on the market by NBE

RTECH Categorical variable: 1 if the NBE uses the rDNA technology; 0 otherwise ${ }^{c}$

STAFFIL Affiliated stars: number of stars affiliated with the NBE at any time 1976$1989^{\text {d }}$

STAFFBEA Sum of affiliated stars: number of stars affiliated with any NBE in the NBE's BEA at any time 1976-1989

STLINKLO Linked local stars: number of stars who (a) are linked to the NBE by coauthorship with a scientist affiliated with the NBE, (b) are located in a university in the NBE's BEA area when such a coauthored article was published, and (c) were not affiliated with the NBE at any time 1976-1989 
Table A.2

Sample Statistics for Variables

\begin{tabular}{|c|c|c|c|c|c|}
\hline Variable & $\mathbf{N}$ & Mean & Std. Dev. & Minimum & Maximum \\
\hline DDEVMKT & 78 & 0.7564 & 0.4320 & 0 & 1 \\
\hline DELEMP & 110 & 100.21 & 456.82 & -383 & 3766 \\
\hline DGROW & 110 & 0.1818 & 0.9205 & -1 & 1 \\
\hline DHUMDI & 78 & 0.5769 & 0.4972 & 0 & 1 \\
\hline DHUMTH & 78 & 0.5897 & 0.4951 & 0 & 1 \\
\hline DNBF & 110 & 0.7909 & 0.4085 & 0 & 1 \\
\hline EMP89 & 110 & 120.67 & 276.47 & 1 & 1800 \\
\hline EMP94 & 110 & 220.88 & 661.36 & 0 & 5400 \\
\hline FIRMAGE & 110 & 7.3091 & 3.1789 & 1 & 14 \\
\hline PRODDVLP & 78 & 1.9615 & 4.2194 & 0 & 22 \\
\hline PRODMKT & 78 & 3.8846 & 5.3500 & 0 & 29 \\
\hline RTECH & 103 & 0.5437 & 0.5005 & 0 & 1 \\
\hline STAFFIL & 110 & 0.0909 & 0.4798 & 0 & 4 \\
\hline STAFFBEA & 110 & 4.1636 & 3.4708 & 0 & 8 \\
\hline STLINKLO & 110 & 0.0636 & 0.3112 & 0 & 2 \\
\hline STUNABEA & 110 & 18.700 & 9.5289 & 0 & 29 \\
\hline STUNTILO & 110 & 18.636 & 9.4643 & 0 & 29 \\
\hline WSAFFIL & 110 & 1.5818 & 13.375 & 0 & 139 \\
\hline WSAFFBEA & 110 & 75.727 & 85.100 & 0 & 172 \\
\hline WSLINKLO & 110 & 0.1545 & 0.8587 & 0 & 7 \\
\hline WSUNABEA & 110 & 204.02 & 153.72 & 0 & 376 \\
\hline WSUNTILO & 110 & 203.86 & 153.54 & 0 & 376 \\
\hline
\end{tabular}


Table A.3

Coverage for 1994 Employment, 1989 Products in Development or on Market, and Use of Recombinant DNA (rDNA) Technology

1994 Telephone Census of California NBE Employment

182 Initial cases (Cal. NBEs, 22 with EMP89 = 0, in Zucker, Darby, and Brewer 1994 data)

43 Disconnected or wrong numbers, no new number found

25 NBEs located from which no response obtained (unable to contact respondent, respondent not in on repeated attempts)

4 NBEs located but explicitly refusing to respond to the survey

110 Usable observations for NBEs (Of which 100 NBEs responded to the survey and 10 NBEs were not located whose death was documented in the Zucker, Darby, and Brewer (1994) data base (1994 employment level set to 0)

1989 Products in Development or on Market

110 Usable observations for NBEs from 1994 Telephone Census

32 NBEs which were not listed in Bioscan for 1990, 1989, or 1991

78 NBEs for which products in development of on the market circa 1989 obtained $^{\text {b }}$

NBEs Using or Not Using rDNA Technology

110 Usable observations for NBEs from 1994 Telephone Census

7 NBEs with data on use of rDNA missing in Zucker, Darby, and Brewer 1994

103 NBEs for which use of rDNA is known

Notes: a. Two of the EMP89 $=0$ NBEs were contacted but refused cooperation beyond saying that their employment was unchanged from 1989. For these apparently very small NBEs we set EMP89 = $\mathrm{EMP94}=1$.

b. Five of the 110 NBEs from the telephone census have missing data both for products in development and on the market and for use of rDNA technology. Thus 76 NBEs have complete data including EMP89, PRODDVLP, PRODMKT, and RTECH. 
Table A.4

Products in Development by California NBEs

Description

Zanaflex ${ }^{\mathrm{TM}}$ AN-021A (tizanidine) to treat spasticity associated with multiple sclerosis or spinal cord injury

In vitro production of entomophagous nematodes for control of navel orange worm

Insect-specific viruses for lepidopterous insects

Excimer laser

DNA probe

Nerve growth factor

NuLysin ${ }^{\mathrm{TM}}$ human lysozyme

IDEC-In2B8 indium-coagulated pan-B imaging agent in Phase I/II clinicals

Doxil $^{\mathrm{TM}}$ Stealth ${ }^{\mathrm{TM}}$ liposome doxorubicin for anticancer in Phase III clinicals for Kaposi's therapy, including Kaposi's sarcoma and AIDS patients

Therapeutics for psychiatric orders

Modified oils-improved nutrition edible oils, industrial lubricants

Stem cell factor

Silicon oil for opthalmics

UPAR (human therapeutic)
Status

submitted NDA (12/93)

not reported

not reported

in Phase I clinicals

in preclinicals

in Phase I clinicals ('92)

in development II clinicals for nonsmall-cell lung cancer

in research phase

in field trials (fall 1991)

in Phase II clinicals

filed PLA

in development

Liposomal daunorubicin (DaunoXome ${ }^{\mathrm{TM}}$ ) for Kaposi's in Phase III clinicals, filed NDA sarcoma

(2/93), granted orphan drug status $(5 / 93)$ 
Imagen ${ }^{\mathrm{TM}} \mathrm{BP}--\mathrm{IV}$ CT contrast agent for blood

Assays for plasma amylin

Arbutamine with GenESA ${ }^{\mathrm{TM}}$ system for diagnosis of coronary artery disease

G-202 for treatment of psoriasis

Renatol $^{\mathrm{TM}}$ LJP-394 to treat lupus (SLE)

Albunex $^{\mathrm{TM}}$ ultrasound contrast imaging agent in Phase I clinicals (10/91), interrupted clinicals $(9 / 92)$

in preclinicals

filed regulatory submission in US and Europe (12/93), plan to file in Canada (1994)

in preclinicals, files US IND (11/92)

in development, to file IND (1994)

completed clinicals in US, Japan, \& Europe, submitted PMA application to the FDA (9/90), \& filed NDA in Japan (through Shionogi) (10/91), \& in the UK (through Hafslund Nycomed AS) (1992)

in development

in preclinicals

Decorin
scarring

Cervical cancer immunotherapeutic

in research phase

Note: Products in development were drawn as a 1-in-10 sample of products listed in the February 1994 issue of Bioscan for listed firms in our sample. 
Table A.5

Products on the Market by California NBEs

\section{Fermentors}

CycleTest Plus DNA kit

Cancer diagnostic imaging therapeutics

Genotropin $^{\mathrm{TM}}$ (second-generation hGH)

ENA Auto ID extractable nuclear antigen test system

CEDIA $^{\mathrm{TM}}$ immunoassay for Digitoxin

Threshold $^{\mathrm{TM}}$ Total DNA assay kit for quantification of DNA in protein solutions

Kits for staining antigens in cells, tissues, or on western blots

IL-2 proleukin

8-MOP ${ }^{\mathrm{TM}}$ (methoxsalen) for cutaneous T cell lymphoma treatment

Endo-Pack ${ }^{\mathrm{TM}}$-PA tissue culture

Specialty diagnostic and pharmaceutical intermediates

First nonisotopic IgE test using MAbs -- Tandem- $E^{\mathrm{TM}}$ IgE

Hepatitis B surface antigen

QTest $^{\mathrm{TM}}$ liposome-based pregnancy diagnostic

Conceive $^{\mathrm{TM}}$ one-step ovulation predictor for OTC ovulation market

ImmunoZap ${ }^{\mathrm{TM}}$ bacteriophage lambda expression vector

VacSYN/FeLV ${ }^{\mathrm{TM}}$ vaccine for feline leukemia virus

$\mathrm{Kephra}^{\mathrm{TM}}$ reversible color-change ultraviolet-sensitive ink

Note: Products on the market were drawn as a 1-in-20 sample of products listed in the February 1994 issue of Bioscan for listed firms in our sample. 


\section{Figure 1: California Stars and Products in Development at NBEs}

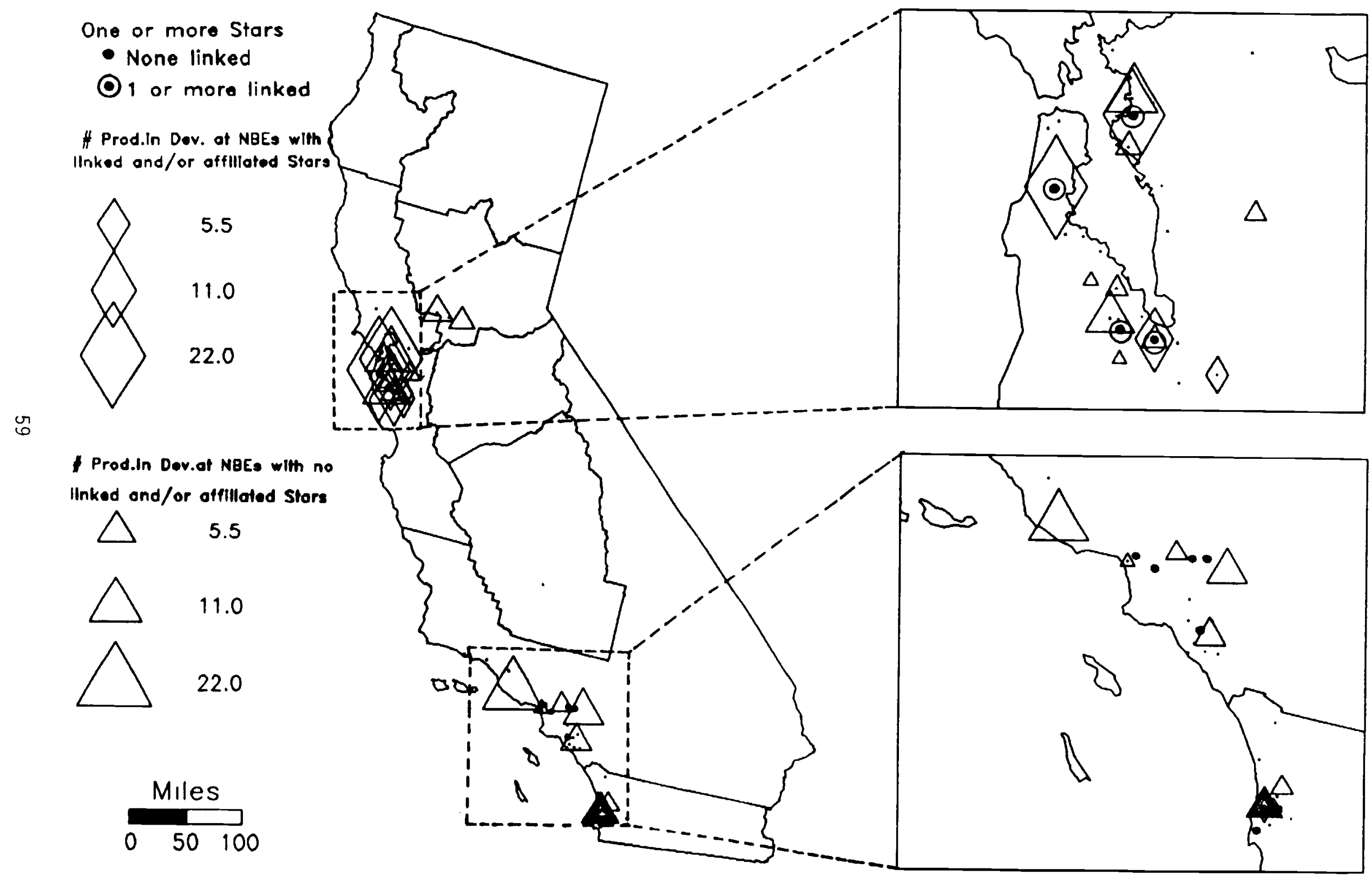

